

RESEARCH PAPER

\title{
A Comparative Analysis of Gender and Educational Leadership in Pakistan and the United Kingdom
}

\section{Yousra Ashraf 1 Syed M. Jaffer Hassan Gardezi* 2 Farheen Saeed ${ }^{3}$}

1. MS Scholar, Department of Humanities, Comsats University Islamabad (Lahore Campus), Punjab, Pakistan

2. Lecturer, Department of Education, Forman Christian College (A Chartered University), Lahore, Punjab, Pakistan

3. Assistant Professor, Writing and Communication Program, Forman Christian College (A Chartered University), Lahore, Punjab, Pakistan

\begin{tabular}{|c|c|}
\hline PAPER INFO & ABSTRACT \\
\hline Received: & This paper considers gender differences in educational \\
\hline July 18, 2021 & leadership theory and practice in two countries: Pakistan and \\
\hline Accepted: & United Kingdom. The differences are highlighted and explored \\
\hline November 20, 2021 & through a comparative analysis of gender roles and its multitude \\
\hline Online: & rtaking the \\
\hline Keywords: & \\
\hline and & nds \\
\hline ship, & he \\
\hline Educational & The \\
\hline Attainment, & rch repeatedly delves into the issue of differential treatment \\
\hline Gen & cluding statistics and other insights to further inform the \\
\hline Differences & main hypothesis of the present research. The breadth of issues \\
\hline *Corresponding & by women from both countries paint two \\
\hline $\begin{array}{l}\text { Author } \\
\text { syedjaffergardezi } \\
\text { @gmail.com }\end{array}$ & $\begin{array}{l}\text { different realities. Moreover, the paper offers solutions in terms } \\
\text { of what work needs to be done towards a more thoughtful } \\
\text { understanding of leadership, in both countries. }\end{array}$ \\
\hline
\end{tabular}

\section{Introduction}

This paper attempts to investigate the significance of gender and leadership in the field of education at a global level. It also looks at gender differences and its effects in the representation of women in educational leadership. For this purpose, two countries Pakistan and the United Kingdom, have been selected as case studies.

Pakistan and United Kingdom are two different countries with former being a developing country whereas the latter being a developed country. Not just this, Pakistan and the UK have religious, cultural, social, and economic differences. The educational system is different too and both these countries have different problems in the field of education. However, in this paper we try not only to draw differences 
but also find the similarities in areas of gender and educational leadership and how gender plays a role in leadership roles in Pakistan and the UK.

If we look at the statistics of the two countries, Pakistan has a total population of 207,684,626 with 51\% males and 49\% females (National Census, 2017). UK on the other hand has a population of $67,215,293$ with $51 \%$ females and $49 \%$ males (The World Bank, 2020). The statistics indicate that almost half of the population in both countries is female however there are huge differences among these two countries in educational context. The UK being a first world country is making advances in the field of education, whereas Pakistan, on the other hand, hosts the highest out of school children in the world, with about 22.8 million children without access to education (UNICEF, n.d.). Out of these 22.8 million, 12 million are girls. Females who manage to go to school, only $13 \%$ of them reach grade 9 (Malala Fund, n.d.). There are various reasons for this, and some of them have been discussed later in this essay.

In the upcoming sections, let's try to investigate the connection between education and cultural change and how gender plays a role in determining leadership roles in Pakistan and the UK.

\section{Education and Cultural Change}

The promise of educational return and the ability to turn the academic success into the societal outcomes such as a steady and substantial income along with a status in the social setup has provided women with the incentive for this rapid improvement in various areas of academic research. In the latter half of the twentieth century feminists (both liberal and radical) were seen challenging these traditional and established gender roles which had a significantly influenced women's ambitions and self-esteem and breaking away from the circle of inhibition. Angela McRobbie conducted a longitudinal study where she compared a women/ girl's magazine and she found out a stark difference of expectations that the women of two different decades had for themselves. In her book The Aftermath of Feminism, McRobbie further adds how this desire for freedom and zest for education was seen as leading the women towards "non- heterosexual lifestyle...a subculture" (McRobbie , 2009) and ambitious women were written off at every turn so as to hamper their efforts to challenge "heterosexist logics" (McRobbie, Feminism and Youth Culture: From Jackie to Just 17., 1991). However, this cultural change is yet to be realized in its complete form in Pakistan.

\section{Gender Issues and Educational leadership in Pakistan}

Robust patriarchal practices in Pakistan have considerably hindered the progress of women in the education sector, and especially in the leadership cadre (Khokhar, 2018). According to a report issued in recent years by Academy of 
Educational Planning and Management, an organization that works and comes under the wing of Ministry of Federal Education and Professional Training, about $59 \%$ of the teaching staff, up to the degree college level happen to be women, as compared to male teachers that make up 46\% (Pakistan Education Statistics 2016-17, 2017).

71.5 per cent of the women in Pakistan happen to be young, with age bracket that ranges from 15-35 years age (National Census, 2017) . Ever since the country's independence from British imperialism in 1947, the status and overall standing of females in Pakistan has changed significantly and are generally found to be enjoying a much better status but the constancy of female oppression cannot be denied. Only 39 per cent of the total Pakistani woman contribute the labor force participation rate with, " 0.63 in literacy rate of females, 26 per cent female presence in parliament (that too on reserved seats, very few women in Pakistan are directly elected to the parliament) and 5 years of female leadership in state out of the last 50 years" (Manzoor, 2015). Besides these significant figures, Pakistan currently holds 141st position out of 142 when it comes to female participation to economic development, 132nd overall position in equal educational attainment. Along with that, the country occupies 119th in health and survival of females and scored the $85^{\text {th }}$ place when it came political empowerment. These prospects paint a grim picture as Pakistan scored 141 out of 142 countries. (Manzoor, 2015).

There is a divide between the male and female students' enrollment rates as observed in the degree colleges i.e., 56\% male students and $44 \%$ female students. (Pakistan Education Statistics 2016-17, 2017). This curve changes and takes a downward turn when it comes to women assuming leadership roles in Higher Educational Institutions, where a scarcity of women leaders and role models has been observed, especially in STEM, engineering and technological sciences related fields, and a female representation is mostly seen in the departments of natural sciences, arts, and humanities. The ratio of female workforce to male workforce in Pakistan is $22 \%$ to $67.8 \%$, which paints an alarming picture as far as the use of human resource capital is concerned (Patchamuthu \& Grown, 2017).

\section{Education leadership trends in the UK}

Comparing it to the educational leadership trends in the UK, at least one in five professors has been reported to be a woman (Yousaf \& Schmiede, 2017). UK currently deals with different sets of issues with more than $50 \%$ of the country's nonprofessorial academic work muscle constituted by the female populace i.e., $46.8 \%$. With only $19.8 \%$ women assuming the professorial position, it bends the odds of representation in the favor of male faculty members. A document released by the University College Union (UCU) looked critically at the current practices in educational leadership and the accompanied changes, with one of the caveats concerned with the slower pace of this transition to equalize the ratio and reducing 
the gap between male and female professor recruitment in Higher Education institutions, which could easily take up to 40 years (University and College Union, 2013) . Just like in Pakistan, female representation in top-tier educational positions (Vice Chancellors, Directors, Heads of Departments) becomes significantly lower in UK than their representation at all other academic level. Many universities in UK have been found struggling in keeping up with this compromised standard of one in five professors being female (Yousaf \& Schmiede, 2017).

\section{Misalignment between education policy and cultural practices}

Education Policies given and implemented by past governments and present body of governance in Pakistan have largely contributed to this notion of differential access to educational leadership positions for men and women. Age old ideologies are still very much intact, and women are still propelled to sacrifice their jobs to strengthen their familial roles and are allowed to enter the areas of professions that are not looked down upon traditionally and are considered as women-oriented jobs by the larger society, mainly teaching and medicine professions (nursing courses and MBBS doctors). Many of these young women never get to see their goals come to fruition as they are married off quiet early after the completion of their baccalaureate level degrees (Ashraf, 2010). However, modifications were made in 1998 and 2009 education policies to promote gender parity by offering equal opportunities and same treatment to men and women. It somehow contributed towards opening new doors for women when it comes to building a career in education and academia (Farah \& Shera, 2007).

The research carried out by (Hofstede, 2001) sheds a light on the influence of cultural context on its leader and those he is supposed to be leading. This relationship informs the practices on the macro, miso and micro education levels as the style and orientation of a leader and his reflections are highly influential when it comes to formation of societal beliefs. According to an article in The News, Pakistan's political leadership and its citizenry have often dismissed the idea women in positions of power, hence, marring the confidence of women in the private spheres of life. This situation of compromised self-confidence is further mirrored in public spheres as well, where taking orders or letting women have a say in matters of importance is considered a mortal sin (Khan , 2020). Studies highlight those social, religious, and cultural conventions and stereotypical role in the larger societal framework impact the overall representation of women in the education setup. Mobility issues, family constraints (on who to associate with), career hiatus, childcare duties, sexual preferences, gender disparity, identity, and cultural politics. Notion around motherhood which is perceived as the highest achievement for a woman in South Asian societies, women's association with the ethics of care, experiences of passive racism and marginalisation of ethnic minorities are some of the contributing factors that result in reduced representation. Scarcity of opportunities, lack of leadership 
training and negative connotations attached to acquiescence towards the leadership position of a woman in a professional setting also shape up the representation of woman in school leadership roles and positions (Mythili, 2017).

\section{System's preference for men}

The partiality of selection committees when it comes to hiring women in the fields of science and technology has taken a form of a phenomena that exists and persists worldwide. Women in Pakistan are more likely to attain jobs in the humanities, social sciences, or arts departments (Khokhar, 2018). The recruitment procedures and the hiring processes of the selection panels make it evident that they find the women's ability to perform questionable and hold their male counterparts in a higher regard. Existing cultural biases and ideologies promote these behaviors, explicitly or implicitly hampering the job prospects of women (Moss-Racusin \& Corrine, 2012). Women are turned down for promotions because according to these hiring committees they are not highly published (Fox, 2010). Consistency of male authors is considerably high thereby, providing them an edge when it comes to landing higher managerial positions that their female counterparts covet (Javin, 2013). It is pertinent to note that science, engineering, and technological education precincts happen to highly male dominated research zones in Pakistan, and this could be attributed to the fact that there is not a single distinguished woman scientist or esteemed researcher of these fields in the country. The journals regarding these subject areas are handled by the editorial boards, which happen to be heavily dominated by a male presence too. Beaten by the number game, women working in these research fields often have to navigate their way in an all-male organizational setup with role models (that range from none or few and far between). This leaves them in a precarious position career-wise with no one to look up to professionally or someone who can offer relevant and sage advice regarding how to climb up the structures that are based on gendered approaches; favoring one male gender over the female one (Nazemi, Mortazavi, \& Borjalilou, 2012).

\section{Gender Pay Gap in Educational Sector in UK and Pakistan}

However, the gender pay divide across academia continues to grow wider in the UK and unveils truth of the dismal situation. In 2019, nine out of ten institutions were reported to be paying their male employees a lot more than their female counterpart, taking the average median pay divide of $13.7 \%$ which $4.6 \%$ higher than the figure of 9.1\% reported in 2018 (Amery, 2019). Moreover, recent research data reveals that $75 \%$ of all women Vice-Chancellors (from Higher Education Institutions) were placed in the last two gross income quartiles, that translate into further problem related to the gender pay divide (National Education Union, 2018). In UK, women face professional barriers in the way of their advancement into leadership at the onset of their careers e.g. by holding a professorship. According to a BBC 2016 report, on average only one in four professors in the UK Higher Education Institutions were 
female, when ironically half of the lecturers happen in these universities happen to be women (Coughlan, 2016). According to an article published by the Diversity and Inclusion website (2020), Male faculty members happen to be a lot more ambitious and show willingness towards enlisting and applying for jobs that are hardly ready for at times whereas the opposite is true for female faculty members. Many researchers in the UK are of the view that hindrances to woman's success can be attributed to biased attitude, lack of ambition (on the woman's part), multiplicity of cultural factors, lack of a guidance and support mechanism which leave them in a position where they lose the power to negotiate. When it comes to education in Pakistan, the ever-increasing gender pay gaps depict a stark reality. Most concerning and worrisome are the facts that these divides were seen to be the widest at lower levels of the educational hierarchy and have seen to be much reduced for secondary and tertiary education levels (Ahmed A. , 2021). Another news report showcased economic opportunities and options for females in the country happen to be minimal when it is struggling to manage and sustain mere 32.7 per cent of the wage inequality that exists and strongly persists between men and women in the workplaces of all fields (Ahmed A. , 2019), which is a direct consequence of male dominance within the subcontinent society, females are regularly discriminated against, resulting in poor representation, specifically when it comes to their place within entrepreneurial ventures and professional positions (Manzoor, 2015). Over the years, many women come to accept their powerlessness. Also, there are those who are not motivated to pursue a job or prosper in a workspace and prefer their domestic roles, including responsibility of childcare, household chores etc. (Side \& Robbins, 2007).

\section{The Issue of Representation}

Gender equity has always shown to have a positive effect on economic growth in all the department namely; education, health care and provision of the basic rights to both gender categories (UNSECO, 2009). The World Bank Organization has rigorously emphasized upon making hefty investments in education of women. It will serve as a technique for further development and poverty eradication in the third world nations as this gives way to improved rates of economic returns and profits (Oxaal, 1997). Empowerment of female population can only be made possible in all domains of life when they are allowed to have their most basic right fulfilled i.e., the right to education (Lopez-Carlos \& Zahidi , 2005). In the last century, more countries have come to realize education as way to build a better world for themselves and are treating it as a priority. Western countries and some other developed countries have made great strides and it shows because many women in these areas affirm the fact that they have attained parity, or at least a semblance of it. However, there are areas of higher education where minimal participation of women is resulting in underrepresentation. To counter it efforts should be made to address the issue on every scale; policy renewal and research wise (Jacobs, 1996). In most of the developed countries women are seeing the aftermath of attaining gender parity as their 
accessibility to higher education has vastly improved, with more and more numbers of female students entering in the departments of tertiary students. Enrolled female proportion in tertiary education stands at $52 \%$ while it remains remarkably low in third world countries and the proportion barely manages to touch $27 \%$ (UNESCO, 2002). According to a recent UNESCO released report, women formed a slightly larger proportion i.e., 53\% of students graduating with Bachelors' and Masters' degrees in 2014. The pace of change remains slow, nearly stagnant and the proportion of female enrollment rate in PhD programs was reported to drop down to $44 \%$ (Bastidas, 2021). Of all the researchers in the world, only 30\% university researchers happen to be women. There is an overabundance of female teaching staff at lower education levels; this overrepresentation stands at $66 \%$ in primary education, $54 \%$ in secondary education and presence in tertiary education sector remains markedly lower with 43\% (Bastidas, 2021).

Men have an overrepresentation in most of the faculty positions in higher education institutes globally. UNESCO reported the female representation in tertiary institutions in developing countries to be as lower as $10 \%$ for Ghana and $18 \%$ for Pakistan (UNESCO, 2002). The gender disparity tends to be higher in the developing countries because all the managerial job posts come under the jurisdiction of males, that guarantees power across the board hence, all the decision-making lies with them and they are given more opportunities of network building (Gracia, 2009).

\section{Recent Shift in Women Participation}

A recent manifestation of this was noticed in the Coronavirus induced lockdown period. According to a news report in The Guardian, women research plummeted to an all-time low. The number of article submissions made from the female members of the academia took a hit and a dramatic drop was seen whereas, men were seen to be thriving as their article submission rate and eventually the acceptance rate increased. Women in Britain have struggled to juggle their workload; domestically and professionally. Their duties with respect to homemaking, childcare and family care has pushed them to walk out on research projects, collaborations or a complete abandonment of research work on their part, thereby slowing their rate of progress compared to their male colleagues who do not have to bear the brunt of these additional duties like for instance, homeschooling their children (Fazackerley, 2020). According to Anna Fazackerley, job promotion in universities necessitates getting published in academic journals and is a crucial measure of determining the successful outcome rate of researchers in the state's standardized Research Excellence Framework, which annually gives a funding of around $£ 2 b n$ to these universities (Fazackerley, 2020). 


\section{Personal and professional barriers to women's progress in Pakistan}

Gender disparity in education has put many women at a disadvantaged position in the countries of South Asia (UNESCO, 2002). World Economic Forum gave (Lopez-Carlos \& Zahidi , 2005) Pakistan 56th slot out of 58 countries showing propensity towards reducing gender inequality. Gender equality policies exist on paper and in legislation, extending both genders the similar rights related to professional environments (NAP, 2004). This mirrors and reflects the socio-cultural premise of major chunk of the South Asian region and the indigenous culture there. Elaborating the continuing assumption of gender role in the country, Khalid (2011) differentiates between two groups; first being the Conservatives, who are in favor of the marginalization of females, and second group; the Liberals, who harbor a firm belief in provision of a democratic role and female freedom.

Quraishi and Kaleem discuss the experiences of female faculty who face gender discrimination as a daily occurrence and consequently suffer in the process with lower job satisfaction rates. Women are hardly ever consulted on matters related to policy and are ousted in decision making processes on regular basis because of sporadic representation on committees and very few of them come to acquire the position of chair (Quraishi \& Kaleem, 2008) These circumstances are a sign of undervaluation of female faculty members, but together with this they impede the sufficient conduit of information towards them. Consequently, female faculty members in the country learn to be content or drop out of their jobs because they are overwhelmed by the personal and professional barriers. All these factors constitute a hierarchical gender inequality model; formed by an extremely conservative national culture, internal familial dynamics, and external structures of the institutions (Bond, 1996).

\section{The Question of Female Representation in Pakistan}

When it comes to higher education workplace, international research performed in relation to decision making, which is characterized by the overall contribution and input of faculty members within the instructional, teaching, and curricular educational arenas and managerial circles (Keung, 2008), indicate a shortage of women as authoritative figures seen in the workspace. Within the current work cultures and scenarios in the world, women are thought of as "not as ambitious" as men and the lack of capability is held responsible for their grim job prospects (Goheer, 2003). Constancy of expectations to become homemakers or house-managers haunt them throughout their lives. Decision making therefore, becomes an all-male domain, and women are not allowed to give their input in policy devising, or in other professional institutions besides higher educational departments, where most of the hired teaching staff happens to be women (Lang, 2010). 
Differential access to training workshops and limited professional development opportunities for women are other roadblocks. (UNSECO, 2009). Women are not allowed to venture into the world of opportunities to develop an insight, regarding knowledge which is acquired formally via professional meet-ups, networking and giving input within these workshops and conferences. It happens largely because security issues and restricted mobility rules imposed on women in general and hence, female faculty members in Pakistan have to slow down and restrict their professional growth as the nature of the customs within the society render it difficult to network socially (Shaukat, Siddiquah, \& Pell, 2014).

\section{Women under-representation; a Global Practice?}

Gender discrimination has also been a regular occurrence in first world countries where biased allocation and unequal distribution of resources is not an uncommon practice (Greenhouse, 2004). In higher education, women's access to resources is largely compromised, albeit if the access is made available to them, then the evidence strongly suggests that females utilize the chances (UNESCO, 2002). Though, the female members

Even though women have experienced successes and have scored major wins in department of higher education in the first world countries, the problem of being under-represented within academic and administrative affairs, particularly in the top tiers of institutions remains an issue that is still ignored (Bond, 1996). Job satisfaction is regarded as a valid indicator of judging the general individual's satisfaction with the job. (Diaz-Serrano \& Cabral, Vieira, 2005). Gender discrimination can reduce the rates of job satisfaction. In the sectors of education, there is a proof of an existence of a direct link between assumed autonomy extended in the work environments and the overall feeling of job contentment. Within Pakistan, radical changes need to be implemented in working environments for females to experience job satisfaction and contentment (Shaukat, Siddiquah, \& Pell, 2014).

\section{Unlearning the Learnt Behavioral Patterns}

Gender gaps in educational achievement have always existed and they persist today in many spheres of academia. They still have their roots intact in the third world countries where much needs to be done when it comes to empowering and educating a girl child. Social class, one's ethnic background and gender go on to exercise a key role in determining the kind of educational experience one goes through. Overall, the levels of academic achievement of both genders have been on a steady rise after World War II and a significant change was seen among women's priorities in the last decade of the twentieth century; the 90s where they came to see educational opportunities as the ladder to the realization of their independence, financial freedom/ security and overall subjective freedom (Shaukat, Siddiquah, \& Pell, 2014). However, there are behavioral patterns specifically in the academic 
achievement domain that have withstood these changes and continue to hold out as they restrict interactions that need to happen. According to Aletha C. Huston not much change has occurred with regards to the subject choice which she has referred to as "sex typing" (Huston, 1985) which means that society has segregated between what subjects are feminine and those that it deems to be masculine where only men would be able to perform. The debate about women's surging motivation rates when it comes to the attainment of higher education has been going on since the end of the last century when a trend of prioritizing their educational aspirations over the prospect of landing a wealthy husband was seen. Andreas Hajdar talks about it in his book Gender and Educational Achievement and discusses how female life-prospects, ambitions and goals saw a reversal during the recent decades, caused mostly by the needs and demands of modernization. Particularly, the reduced social and economic significance of the institution of marriage and the rising demand of labor force participation gave them opportunities to have a vocation to be something other than housewives and house helpers. The demand and will to earn one's own bread and butter, coupled with the institutional change of the educational and social framework that made education all the more appealing to both women and men (Hajdar, 2014).

\section{Conclusion}

Gender plays a major role in determining leadership roles both in Pakistan and the UK and there's a long way to reach the point of equality in both countries. Both Pakistan and the UK continue to face different challenges not just in their educational systems but in general, and it is the need of the hour to have equal opportunities especially in leadership positions.

Pakistan being a patriarchal society has its own challenges to overcome. It is very unfortunate that there still are areas where girls are not allowed to attend schools especially in the tribal areas. Not just education, but in such areas, women are not even allowed to exercise their other democratic and constitutional rights. Voting in elections and filing for divorce are two examples of this. Although the situation is very different in the rest of the country, but women continue to face oppression and resistance in every walk of life. Men are given priority and that is major part of the reason as to why there are lesser women seen holding the leadership positions in Pakistan. Gender discrimination is present in the UK too and women continue to face resistance.

It is the need of the hour that we think above aur gender differences and work together to create an environment where there are equal opportunities for everyone, irrespective of gender and social classes. Pay gap is another issue that needs to be addressed. Societal norms also need to be changed and challenged and we should normalize having women on higher positions. Every individual should be assessed on this basis of his/ her skills and not based on his/ her gender or social class or 
religious affiliation (which continues to be a serious problem in Pakistan where people judge you based on which sect you belong to or which faith you follow). We should all aim to work together and play our role in making this world a peaceful place to live - a world free from inequality, injustice, resistance, and oppression. 


\section{References}

Ahmed, A. (2019, December 17). Pakistan ranks 151 out of 153 on global gender parity index: World Economic Forum report. DAWN

Ahmed, A. (2021, March 31). Pakistan loses two spots on Global Gender Gap Index, slides into ranks of worst four countries. DAWN

Amery, F. (2019, April 25). Why Do Uk Universities Have Such Large Gender Pay Gaps? Political Studies Association.

Ashraf, D. (2010). Women Teaching and Leading in Pakistan: Exploring the Challenges and Possibilities. More and Better Teacher for Quality Education for All: Identity and Motivation, Systems and support, 165-73. Brighton: Collaborative Works.

Bastidas, Y. (2021, March 8). Unesco Iesalc Report Asserts That Gender Inequality In Higher Education Remains A Universal Issue. UNESCO

Bond, S. (1996). Women in leadership positions in higher education: Strategies for change. Management development for women in higher education.

Coughlan, S. (2016, September 21). Are universities secretly sexist? BBC News

Diaz-Serrano, \& Cabral, Vieira. (2005). Low pay, higher pay and job satisfaction within the European Union: Empirical evidence from fourteen countries. IZA Discussion Papers No.1558, Institute for the Study of Labour (IZA).

Farah, I., \& Shera, S. (2007). Female education in Pakistan: A review. Gender and education in Pakistan, 03-42.

Fazackerley, A. (2020, May 12). Women's research plummets during lockdown - but articles from men increase. The Guardian

Fox, M. F. (2010). Women and men faculty in academic science and engineering: Social-organizational indicators and implications. American Behavioral Scientist, 997-1012.

Goheer, N. (2003). Women entrepreneurs in Pakistan: How to improve their bargaining power. Geneva: International Labour Organization.

Gracia, L. (2009). Employability and higher education: contextualizing female students' workplace experiences to enhance understanding of employability development, Journal of Education and Work, 22 (4), 301-318 
Greenhouse, S. (2004, August, 18). Woman sues Costco, claiming sex bias in promotions. The New York Times

Hajdar, A. (2014). Gender and educational achievement. Educational Research, 117125.

Hofstede, G. (2001). Culture's consequences: Comparing values, behaviors, institutions and organizations across nations. Sage Publications

Huston, A. (1985). The development of sex typing: Themes from recent research. Developmental Review, 1-17.

Jacobs, J. A. (1996). Gender inequality and higher education. Annual Review of Sociology, 153-85.

Javin, W. (2013). The role of gender in scholarly authorship. PloS one 8.7.

Keung, C. (2008). The effect of shared decision-making on the improvement in teachers' job development. New Horizons in Education.

Khalid, R. (2011). Changes in Perception of Gender Roles: Returned Migrants. Pakistan Journal of Social and Clinical Psychology, 16-20.

Khan, T. (2020, May 5). Women in Power. The News International

Khokhar, A. J. (2018). Women Academic Leaders in Higher Education in Pakistan: Perspectives of Female Students Enrolled in Higher Education Degrees. Department of Education Forman Christian College University, Lahore

Lang, S. (2010). A gender perspective on educational facilities.

Lopez-Carlos, A., \& Zahidi, S. (2005). Women's empowerment: Measuring the global gender gap. Geneva: World Economic Forum.

Manzoor, S. (2015). The impact of indigenous culture on female leadership in Pakistan. International Journal of Organizational Leadership. Volume 4, Issue 4, 414429

McRobbie, A. (2009). The Aftermath of Feminism: Gender, Culture, and Social Change. SAGE, 184.

McRobbie, A. (1991). Feminism and Youth Culture: From Jackie to Just 17. Macmillan: London. 
Moss-Racusin, \& Corrine, A. (2012). Science faculty's subtle gender biases favor male students. Proceedings of the national academy of sciences.

Mythili, N. (2017). Representation of Women in School Leadership Positions in India. Dehli: National University of Educational Planning and Administration.

NAP. (2004). The Constitution of the Islamic Republic of Pakistan. Islamabad: National Assembly of Pakistan. NAP.

National Census. (2017). Retrieved from Pakistan Bureau of Statistics: www.pbs.gov.pk

National Education Union. (2018, December 18). Gender Pay Gap. https://neu.org.uk/policy/gender-pay-gap

Nazemi, S., Mortazavi, S., \& Borjalilou, S. (2012). Investigating factors influencing women's inclination in adopting managerial positions in Iranian higher education. Interdisciplinary Journal of Contemporary Research in Business, 722-732.

Oxaal, Z. (1997). Education and poverty: A gender analysis. Report prepared for the Gender Equality Unit, Swedish International Development Cooperation Agency (SIDA). Retrieved from http://www.bridge.ids.ac.uk/reports/re53.pdf

GOP.(2017). Pakistan Education Statistics 2016-17. Islamabad: Academy of Educational Planning and Management.

Patchamuthu, I., \& Grown, C. (2017). Women in the Workfoce. Business Recorder.

Quraishi, U., \& Kaleem, R. (2008). Gender based faculty development model for higher education. Oxford Business \& Economics Conference, June 22-24, Oxford: Oxford University.

Shaukat, S., Siddiquah, A., \& Pell, A. W. (2014). Gender discrimination in higher education in Pakistan: A survey of university faculty. Eurasian Journal of Educational Research, 109-126.

Side, K., \& Robbins, W. (2007). Institutionalizing inequalities in Canadian universities: The Canada research chairs program. NWSA Journal, 163-181.

UNESCO. (2002). Women and management in higher education: A good practice handbook Follow-up to the World Conference on Higher Education (Paris 5-9 October 1998). 
University and College Union. (2013). The Position of Women and BME Staff in Professorial Roles in UK HEIS.

UNSECO. (2009). World conference on higher education: The new dynamics of higher education and research for societal change and development. UNSECO.

Yousaf, R., \& Schmiede, R. (2017). Barriers to women's representation in academic excellence and positions of power. Asian Journal of German and European Studies. 2, 2 (2017). https:/ / doi.org/10.1186/s40856-017-0013-6 